\title{
Automatic Control of Sliver Thickness by High-Frequency Capacitance Measuring Principle.
}

\author{
Part 3: Measuring of Control System Property and Designing of Controller. \\ By Motozo Ihara* and Bunji Sato**, Members, TMSJ \\ * Shizuoka University, Hamamatu and** The Textile Research Institute of the \\ Japanese Government, Yokohama
}

Based an Jaurnal of the Textile Machinery Society of Japan, Vol. 19, No.5, T12-15 (1966); Vol. 19, No. 5, T16-22 (1966); Vol. 19, No. 7/8, T17-24 (1966)

\section{Abstract}

We measured the dynamic property of each component part of our control system with the following results:

(1) Transfer function $G_{d}(S)$ of the detector is:

$$
G_{d}(s)=\frac{k_{d}\left(1+T_{e} s\right) e^{-L d s}}{\left(1+T_{d} s\right)\left(1+T_{c} s\right)}
$$

(2) Transfer function $G_{f}(s)$ of the final control element is:

$$
G_{f}(s)=\frac{k_{f} \omega^{2} n a \cdot G_{N}(h /|a|)}{\left(1+T_{1 v} s\right)\left(1+T_{2 v} s\right)\left(s^{2}+2 \varsigma_{a} \omega_{n a} s+\omega^{2} n a\right)}
$$

(3) Open-loop transfer function $G_{t}(s)$ of the control system, except the controller, is: $G_{t}(s)=G_{p}(s) \cdot G_{d}(s) \cdot G_{f}(s)$

(4) Specifications of a PID controller which we designed by the Ziegler-Nichols mehod from the open loop transfer function are:

$$
\begin{array}{lll}
P & : 0.3-20 & \text { Continuous variable } \\
T_{I}: 0.3-10 \mathrm{sec} & \text { Steplessly variable } \\
T_{D}: 0.1-5 \mathrm{sec} &
\end{array}
$$

\section{Introduction}

The configuration of the control system dealt with in this article was explained in Part 1. [1] The present instalment gives the results of measurement of the characteristics of both individual and whole elements that make up our control system. We measured, first, the dynamic property of each individual component part element of the control system, then the whole open-loop control system by the frequency response method. With these results as a basis, we express their dynamic properties in terms of transfer functions.

From the open-loop transfer function we calculated the stability limit and the periodic time of sustained oscilations. We measured the practical periodic time on the closedloop control system and compared it with a value calculated under the same conditions.

Finally, with the aid of the measured stability limit and periodic time, we designed an electronic PID controller suited for use on this control system.

\section{Detector}

As we said in Part 1, electric capacitance-type equipment on the small-capacitance measuring principle was intended for use as a detecting element for the control system, but it could not be used as such without a modification, because of violent variations in the zero point (the socalled "drift") with changes in the temperature of the measuring electrode.
We, therefore, designed a device to compensate for the "drift" automatically. The compensator, an accessory to the detecting part, has two input terminals, as shown in Fig. 1: one connected to the output of the small-capacitance measuring equipment; the other to the output of the measuring roller which detects the thickness of delivered slivers by measuring its mechanical displacement. The two inputs combine to make the output of the detector after the former input passes through a high-pass filter and the latter through a low-pass filter.

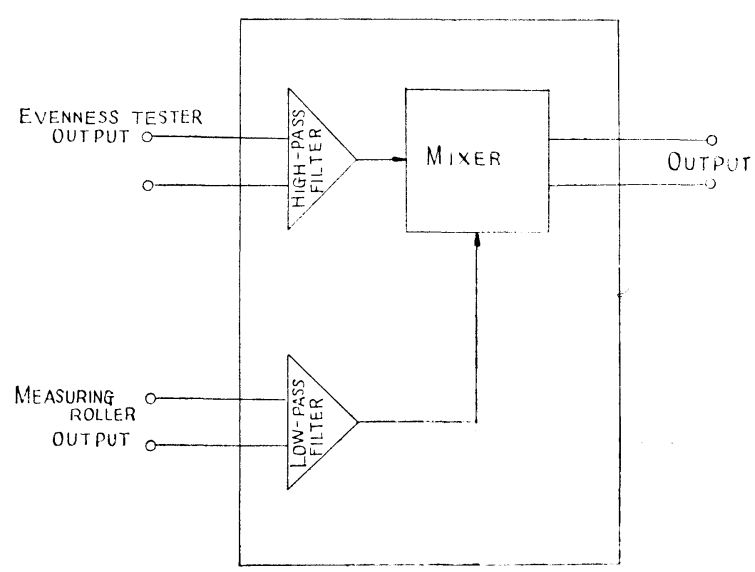

Fig. 1 Principle-diagram of "drift" compensator 
Generally, the "drift" is a low-frequency signal and does not show up in the output of the detector, even if it does in the small-capacitance measuring equipment. The detector, designed on this principle, has been proved by experiment to compensate for the "drift" adequately.

It has been made clear by the frequency response method that the dynamic property of the whole detector, including the accessory element, is expressible in the following transfer function:

$$
G_{d}(s)=\frac{k_{d}\left(1+T_{e} s\right) e^{-L d s}}{\left(1+T_{d} s\right)\left(1+T_{c} s\right)} \quad \ldots \ldots
$$

where

$$
\begin{aligned}
& k_{d} \quad: \text { Gain of the detector } \\
& T_{d} \quad: \text { Time constant of the small-capacitance } \\
& \text { measuring device } \\
& T_{c} \text { and } T_{e}: \text { Time constants of the phase-advance } \\
& L_{d} \quad: \text { Delay in detection }\left(=5.5 \mathrm{~cm} / V_{f}\right) \\
& V_{f} \quad: \text { Surface velocity of the front roller }
\end{aligned}
$$

\section{Final Control Element}

The final control element that varies the surface velocity of the front roller, as described in Part 1 [1], consists mainly of an electro-hydraulic power actor and a PIV speed variable device. Its make-up is shown in Fig. 2 and its outside view in Fig. 3.

In the light of the measured results obtained by the frequency response method, the property of the final control element is expressible in the following transfer function:

$$
\begin{aligned}
G_{f}(s)= & G_{a}(s) \cdot G_{n}(h / a) \cdot G_{r}(s) \\
= & k_{a} \cdot k_{r} \omega^{2}{ }_{n a} \cdot G_{n}(h / a) \\
& \left(s^{2}+2 \xi_{a} \omega_{n a} s+\omega^{2}{ }_{n a}\right)\left(1+T_{1 n} s\right)\left(1+T_{2 v} s\right)
\end{aligned}
$$

where

$$
\begin{aligned}
& G_{f}(s) \quad: \text { Transfer function of final control } \\
& G_{a}(s) \quad \text { : Transfer function of electro-hy- } \\
& \text { draulic power actor } \\
& G_{v}(s) \quad \text { : Transfer function of PIV speed } \\
& \text { variable device } \\
& G_{n}(h / a) \text { : Description function of back-lash }
\end{aligned}
$$

Fig. 4 shows a block-diagram of the final control system.

\section{Designing of Controller}

4-1. Calculating Open-loop Transfer Function, Stability Limit and Periodic Time of Sustained Oscilations.

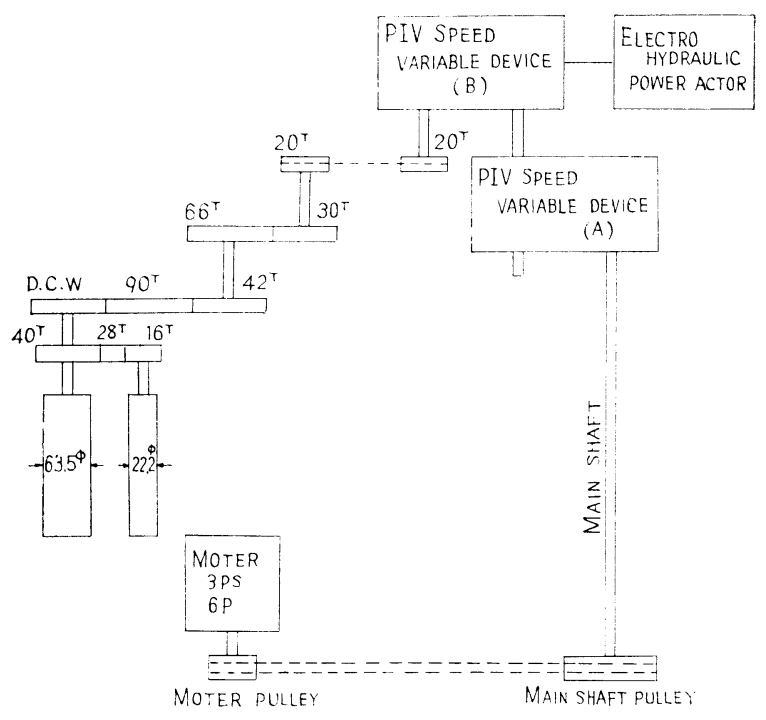

Fig. 2 Constituted diagram of final control element.

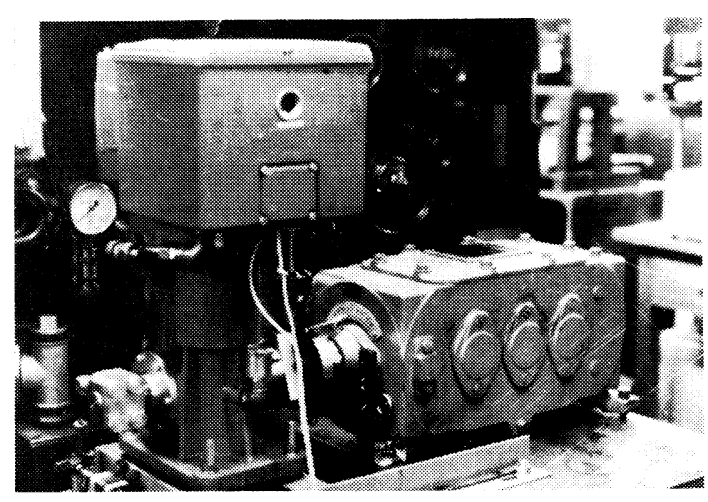

Fig. 3 Outside view of final control element

It is clear from the measured results obtained by the frequency response method that the transfer function of each component part of the control system, if it is in a frequency range of less than $20 \mathrm{rad} / \mathrm{sec}$, is expressible as follows:

Controlled process [2]

Process for control

$$
G_{p}(s)=\frac{k_{p} \omega^{2}{ }_{n p}\left(1+T_{p} s\right)}{s^{2}+2 \xi_{p} \omega_{n p} s+\omega^{2}{ }_{n p}}
$$

Detecting part

$$
G_{d}(s)=\frac{k_{d} e^{-L d s}\left(1+T_{c} s\right)}{\left(1+T_{d} s\right)\left(1+T_{e} s\right)}
$$

Final control element

$$
G_{f}(s)=\frac{k_{f} \omega^{2}{ }_{n a} \cdot G_{n}(h / a)}{\left(1+T_{1 v} s\right)\left(1+T_{2 v} s\right)\left(s^{2}+2 \xi_{a} \omega_{n a} s+\omega^{2}{ }_{n a}\right)}
$$

Journal of The Textile Machinery Society of Japan. 
Disturbance element [3]

$$
G_{n}(s)=\frac{k_{n} \omega^{2} n_{p}\left(1-T_{n} s\right)}{s^{2}+2 \xi_{p} \omega_{n p} s+\omega^{2}{ }_{n p}}
$$

Accordingly, the block-diagram of a constituted control system is as shown in Fig. 5, while open-loop transfer function $G_{t}(s)$ of the control system without a controller is expressible as follows:

$$
\begin{array}{r}
G_{t}(s)=G_{p}(s) . G_{d}(s) \cdot G_{f}(s) \quad \ldots \ldots \ldots \ldots \ldots \\
=\frac{k_{t} \omega^{2}{ }_{n p}\left(1+T_{p} s\right) e^{-L d s}\left(1+T_{c} s\right)}{\left(s^{2}+2 \xi_{p} \omega_{n p} s+\omega^{2}{ }_{n p}\right)\left(1+T_{a} s\right)\left(1+T_{e} s\right)} \\
\cdot \frac{\omega_{n a}^{2} \cdot G_{n}(h /|a|)}{\left(1+T_{1 v} s\right)\left(1+T_{2 v} s\right)\left(s^{2}+2 \xi_{a} \omega_{n a} s+\omega^{2}{ }_{n a}\right)}
\end{array}
$$

where $k_{t}$ is the open-loop gain of the control system.

The measured values of the constants in eq. (9) are given by Tables 1 and 2 . Table 1 shows the values measured at "high temperature and humidity"; Table 2, at "low temperature and humidity." [2]

On the basis of the measured values, we calculated the gain and phase delay of $G_{t}(s)$ and express them in a Bode diagram in Figs. 6 and 7.

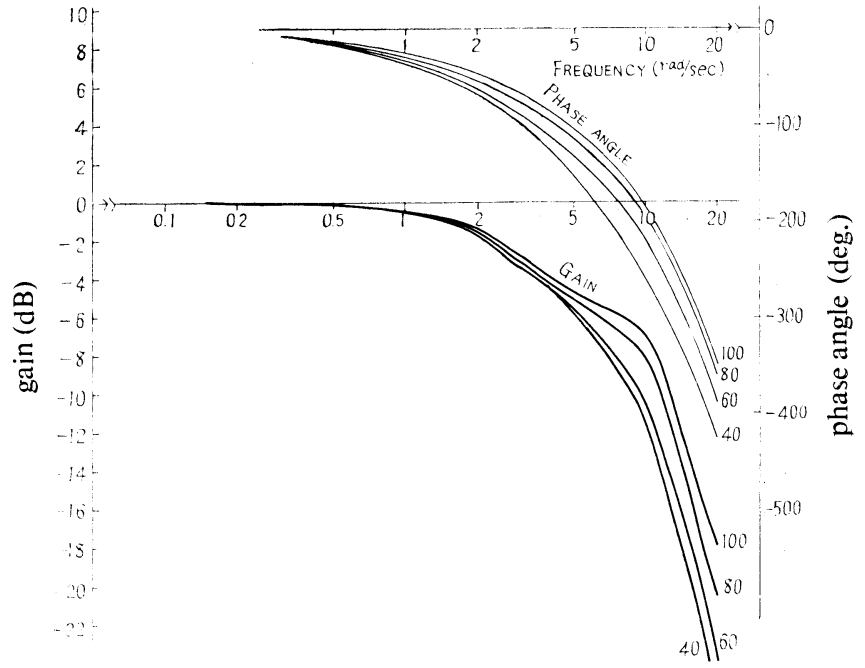

Fig. 6 Bode-diagram of open-loop transfer function

(High temperature and humidity).
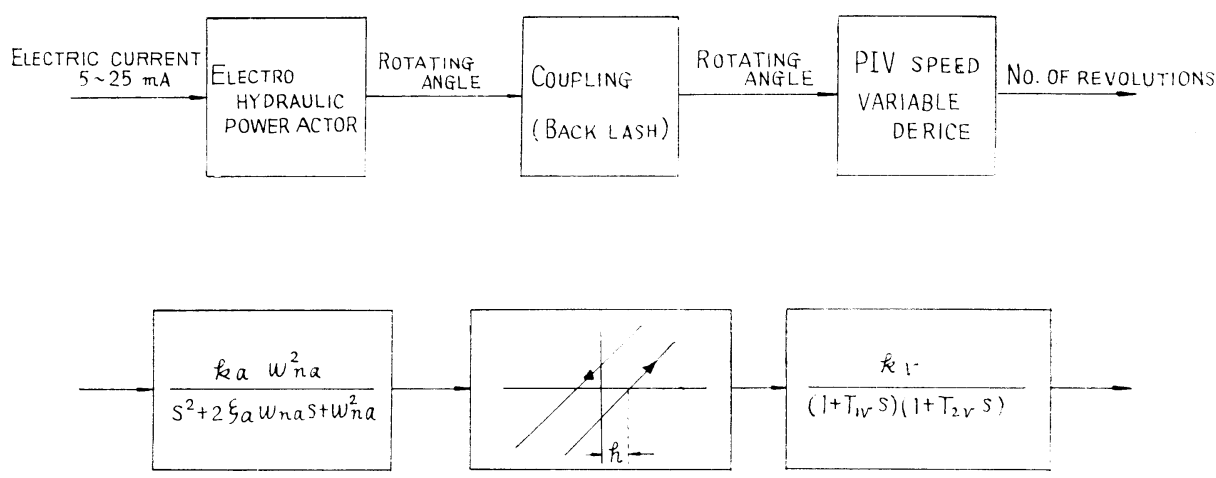

Fig. 4 Block-diagram of whole final control element.
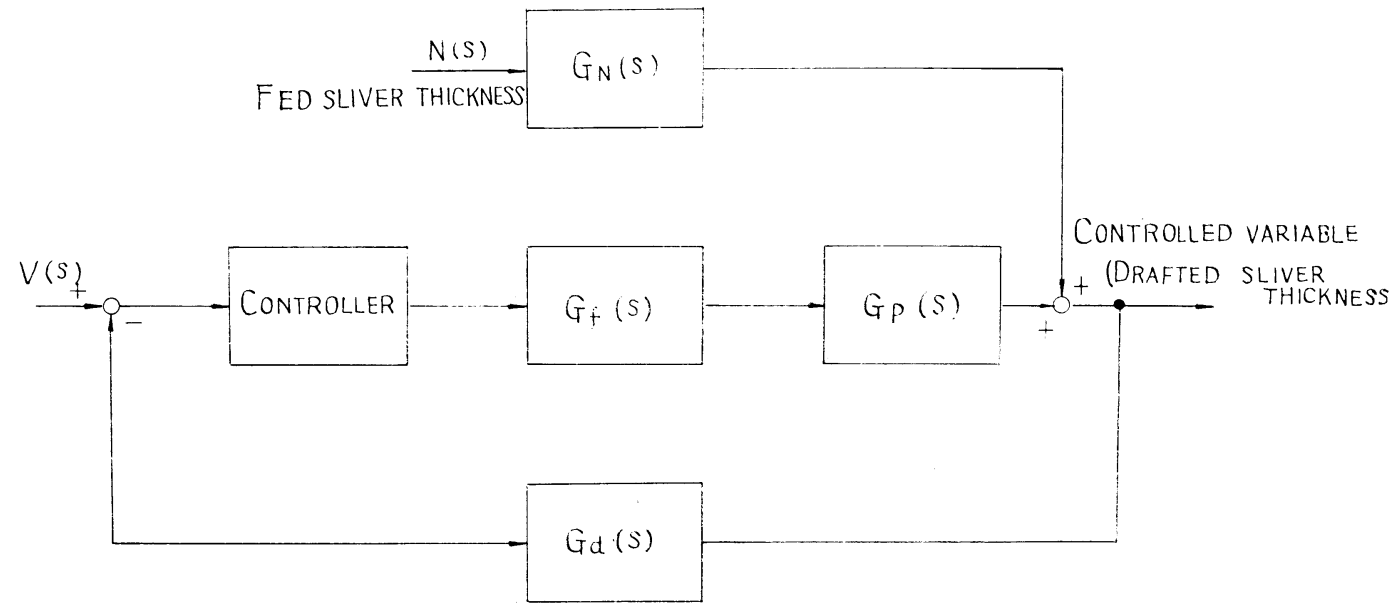

Fig. 5 Block-diagram of control system. 


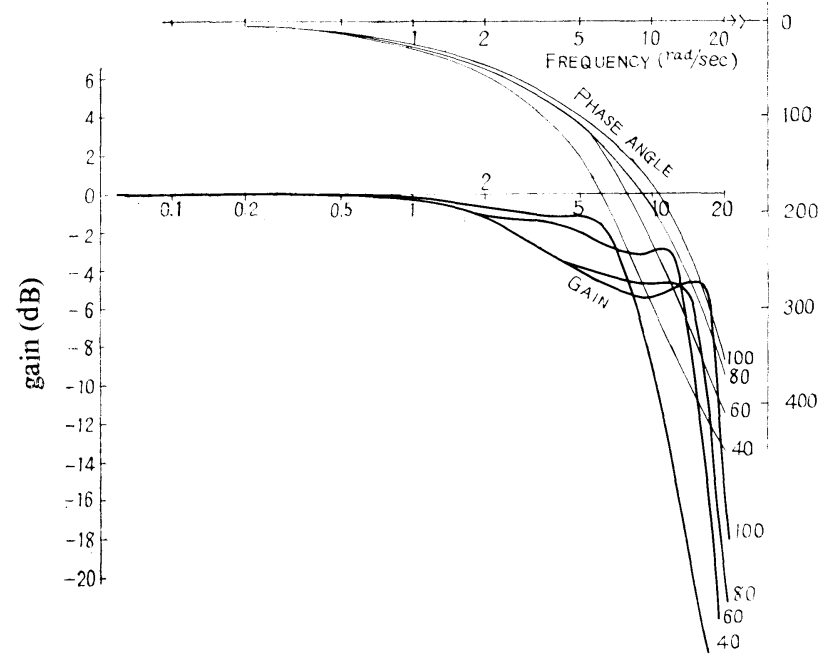

Fig. 7 Bode-diagram of open-loop transfer function (Low temperature and humidity)

Table 1 Measured Values of Constants of $G t(s)$ (at "High Temperature and Humidity")

\begin{tabular}{|c|c|c|c|c|c|c|}
\hline $\begin{array}{l}\text { Surface } \\
\text { velocity } \\
\text { of front } \\
\text { roller } \\
(\mathrm{cm} / \mathrm{sec})\end{array}$ & $\begin{array}{l}\text { Surface } \\
\text { velocity } \\
\text { of back } \\
\text { roller } \\
(\mathrm{cm} / \mathrm{sec})\end{array}$ & $\begin{array}{c}\omega_{n a} \\
(\mathrm{rad} / \mathrm{sec})\end{array}$ & $\therefore p$ & $\begin{array}{r}T_{p} \\
(\mathrm{sec})\end{array}$ & $\begin{array}{r}L_{d} \\
(\mathrm{sec})\end{array}$ & Others \\
\hline 40 & 13.2 & 13.6 & 0.50 & 0.06 & 0.14 & $k_{t}=1$ \\
\hline 60 & .. & 14.7 & 0.43 & 0.08 & 0.09 & \\
\hline 80 & .. & 15.0 & 0.33 & 0.10 & 0.07 & $\begin{array}{l}T_{1 v}=0.33 \mathrm{sec} \\
T_{2 v}=0.11 \mathrm{sec}\end{array}$ \\
\hline 100 & ." & 15.3 & 0.27 & 0.12 & 0.055 & $\begin{array}{c}5 \omega_{n a}=42.0 \\
\xi_{a}=0.33\end{array}$ \\
\hline
\end{tabular}

Table 2 Measured Values of Constants of $G_{t}(s)$ (at "Low Temperature and Humidity")

\begin{tabular}{|cccc}
$\begin{array}{l}\text { Surface velocity } \\
\text { of front roller } \\
(\mathrm{cm} / \mathrm{sec})\end{array}$ & $\begin{array}{c}\omega_{n p} \\
(\mathrm{rad} / \mathrm{sec})\end{array}$ & $\xi_{p}$ & $\begin{array}{c}T_{p} \\
(\mathrm{sec})\end{array}$ \\
\hline 40 & & & \\
60 & 7.5 & 0.37 & 0.20 \\
80 & 9.8 & 0.28 & 0.18 \\
100 & 13.0 & 0.27 & 0.14 \\
\hline
\end{tabular}

The upper curves in these figures show phase delay and the lower curves, the gains of open-loop transfer function $G_{t}(s)$. The figures added near the curves express the surface velocity of the front roller (mean value). We excluded the back-lash from calculation.

With the aid of the Bode-diagram we investigated the stabiltiy limit and the periodic time of oscilations, with the results given Tables 3 and 4 .

4-2. Measuring Periodic Time of Sustained Oscilation

We actually measured the periodic time of sustained oscilations when fed slivers were being drafted with the control system at work, and conpared it with the value
Table 3 Stability Limit and Periodic Time of Sustained Oscilation (at "High Temperature and Humidity")

\begin{tabular}{|c|c|c|c|c|c|}
\hline \multirow{2}{*}{$\begin{array}{c}\text { Surface } \\
\text { velocity } \\
\text { of front } \\
\text { roller } \\
(\mathrm{cm} / \mathrm{sec})\end{array}$} & \multirow{2}{*}{$\begin{array}{c}\begin{array}{c}\text { Draft } \\
\text { ratio }\end{array} \\
\text { (calculated) }\end{array}$} & \multirow{2}{*}{$\begin{array}{l}\text { Stability } \\
\text { Gain }\end{array}$} & \multirow{2}{*}{$\underset{\mathrm{dB}}{\operatorname{Limit}}$} & \multicolumn{2}{|c|}{ Sustained Oscilations } \\
\hline & & & & Frequency & Period \\
\hline $\begin{array}{r}40 \\
60 \\
80 \\
100 \\
\end{array}$ & $\begin{array}{l}3.02 \\
4.57 \\
6.05 \\
7.56 \\
\end{array}$ & $\begin{array}{l}2.01 \\
2.40 \\
2.46 \\
2.21 \\
\end{array}$ & $\begin{array}{l}6.6 \\
7.6 \\
7.8 \\
6.9 \\
\end{array}$ & $\begin{array}{l}7.6 \\
9.0 \\
9.8\end{array}$ & $\begin{array}{l}1.05 \\
0.83 \\
0.70 \\
0.61 \\
\end{array}$ \\
\hline \multicolumn{6}{|c|}{$\begin{array}{l}\text { Table 4. Stability Limit and Periodic Time of Sustained Oscila- } \\
\text { tion (at "Low Temperature and Humidity") }\end{array}$} \\
\hline \multicolumn{2}{|c|}{$\begin{array}{l}\text { Surface velocity } \\
\text { of front roller } \\
(\mathrm{cm} / \mathrm{sec})\end{array}$} & \multicolumn{2}{|c|}{$\begin{array}{l}\text { Stability } \\
\text { Gain }\end{array}$} & $\begin{array}{c}\text { Sustained } \\
\text { Frequency } \\
\text { (rad/sec) }\end{array}$ & $\begin{array}{l}\text { scilation } \\
\text { Period } \\
\text { (sec) }\end{array}$ \\
\hline & $\begin{array}{l}40 \\
60 \\
80 \\
00\end{array}$ & $\begin{array}{l}1.21 \\
1.45 \\
1.72 \\
1.78\end{array}$ & $\begin{array}{l}1.6 \\
3.2 \\
4.7 \\
5.0\end{array}$ & $\begin{array}{r}6.0 \\
7.6 \\
9.0 \\
10.3\end{array}$ & $\begin{array}{l}1.05 \\
0.83 \\
0.70 \\
0.61\end{array}$ \\
\hline
\end{tabular}

calculated from the Bode-diagram under the same conditions.

a. Conditions and Method of Measurement

We drafted a fed sliver of the least possible unevenness with a drafting frame equipped with the automatic control device set in proportional motion. We increased the gain of the controller gradually, so that sustained oscilations occurred on the control system and the drafted sliver had periodic unevenness. We measured the periodic time by using the autocorrelation function of the drafted sliver. We used the same kind of sliver and the same conditions as in Tables 1 and 2 in Part 2. [2]

Before making the experiments, we investigated whether there were limit cycles on the control system, because we were not sure whether the Ziegler-Nichols method was applicable even if there were limit cycles. The investigation was made as in Fig. 8, in which are drawn both a Nyquist

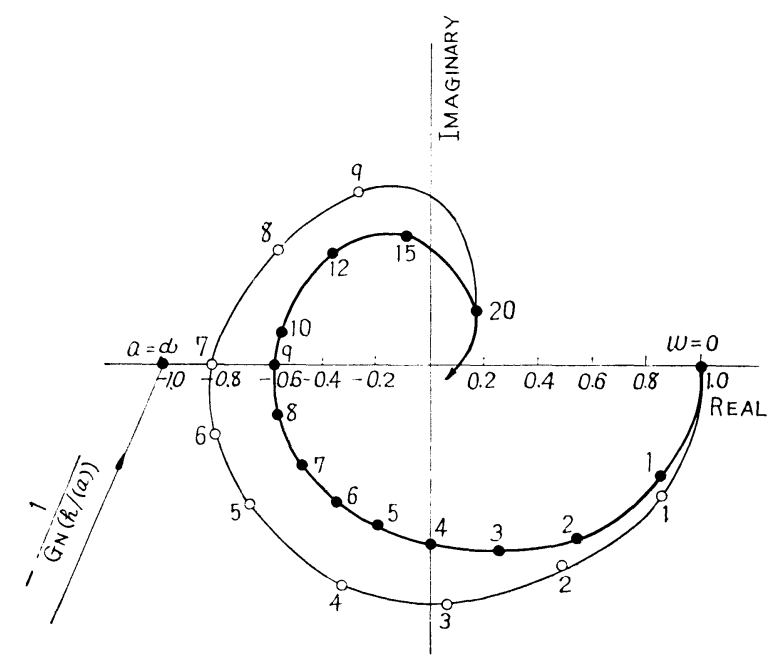

Fig. 8 Nyquist plot of open-loop frequency transfer function and locus of negative reversed description function of back-lash. 
plot of open-loop frequency transfer function $G_{t}(s)_{s}=j w$ and the locus of a negative, reversed description function of the back-lash, $-1 /\left[G_{n}(h / a \mid)\right]$. We were satisfied that there were no limit cycles on the control system.

b. Measured Results

A recorded example of the unevenness of the drafted sliver with periodic unevenness is given in Fig. 9. A recorded example of the autocorrelation function is given in Fig. 10.

The measured values of the periodic time are shown in Fig. 11. The circles in it indicate the measured values; the solid and broken lines express values calculated from the transfer function of the control system. These results show that the measured values almost agree with the calculated values.

\section{4-3. Designing of Controller}

We obtained Table 5 by calculating the optimal gain, integral and differential time. The "Optimal gain" columns contain sets of two figures: the upper figures are values at "high temperature and humidity"; the lower figures,

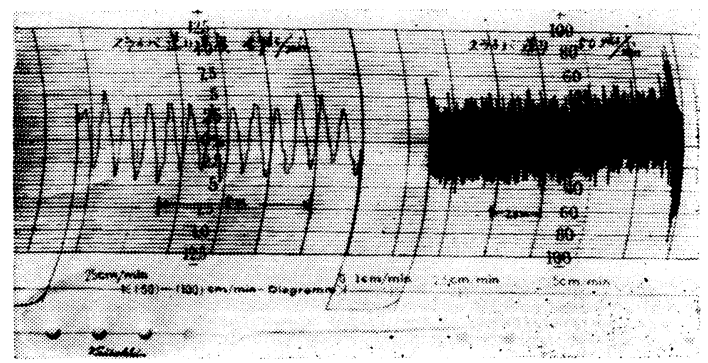

Fig. 9 Recorded sample of drafted sliver having sustained oscilated unevenness.

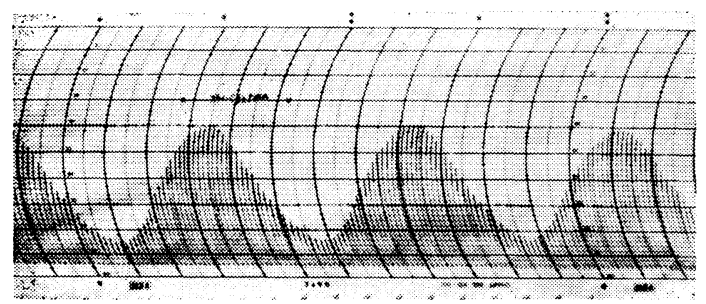

Fig. 10 Recorded sample of autocorrelation function of draftet sliver having oscilated unevenness values at "low temperature and humidity."

Using these figures in Table 5 as a basis, we designed an electric PID controller. Its block-diagram is as in Fig. 12 (b).

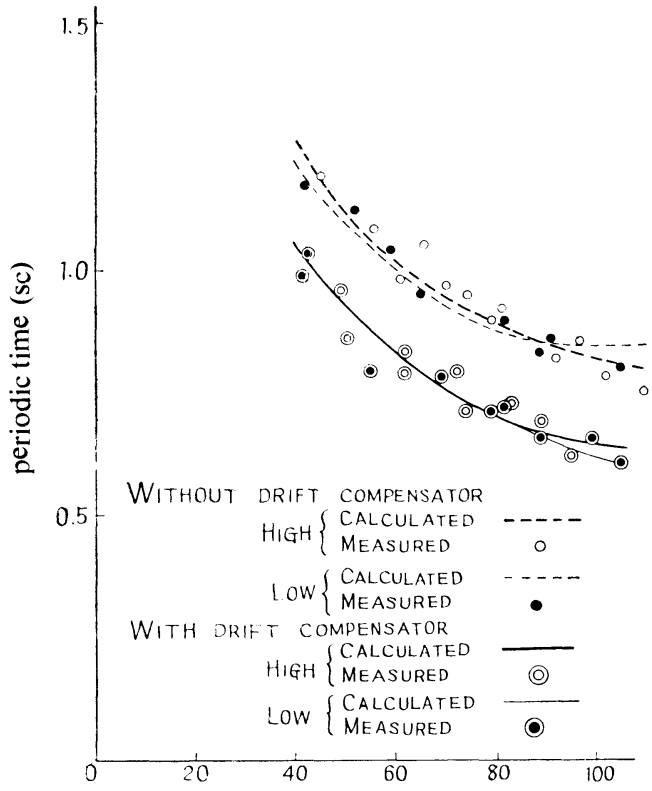

surface velocity of front roller $(\mathrm{cm} / \mathrm{sec})$

Fig. 11 Relation between surface velocity of front roller and periodic time of sustained oscilations

Table 5. Optimal Condition Calculated by Ziegler-Nichols Method

\begin{tabular}{cccccccc}
$\begin{array}{c}\text { Surface } \\
\text { velocity } \\
\text { of front } \\
\text { roller }\end{array}$ & $\begin{array}{c}\text { P Action } \\
\text { Optimal }\end{array}$ & $\begin{array}{c}\text { PI Action } \\
\text { Optimal }\end{array}$ & $\begin{array}{c}\mathrm{T}_{\mathrm{I}} \\
\text { Gain }\end{array}$ & $\begin{array}{c}\text { PID Action } \\
(\mathrm{sec})\end{array}$ & $\begin{array}{c}\text { Optimal } \\
\text { Gain }\end{array}$ & $\begin{array}{c}\mathrm{T}_{\mathrm{I}} \\
(\mathrm{sec})\end{array}$ & $\begin{array}{c}\mathrm{T}_{\mathrm{D}} \\
(\mathrm{sec})\end{array}$ \\
\hline 40 & 1.01 & 0.90 & 0.87 & 1.21 & 0.53 & 0.13 \\
& 0.61 & 0.54 & & 0.73 & & \\
60 & 1.20 & 1.08 & 0.69 & 1.44 & 0.41 & 0.10 \\
& 0.73 & 0.65 & & 0.87 & & \\
80 & 1.23 & 1.11 & 0.58 & 1.48 & 0.35 & 0.09 \\
& 0.86 & 0.77 & & 1.03 & & \\
100 & 1.11 & 0.99 & 0.53 & 1.33 & 0.32 & 0.08 \\
& 0.89 & 0.80 & & 1.07 & & \\
\hline
\end{tabular}

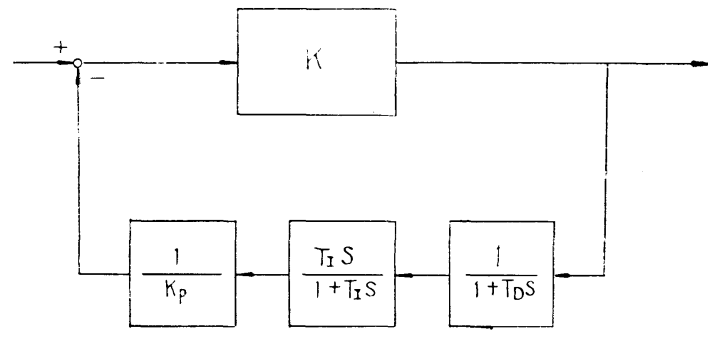

(a) General PID Controller

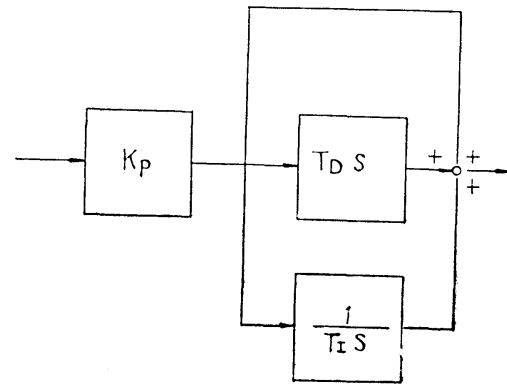

(b) Ideal PID Controller

Fig. 12 Block-diagram of PID controller 
Its specifications are:

$$
\begin{array}{ll}
P & : 0.3-20 \text { (Proportional band } 300-5 \% \text { ) } \\
T_{I} & : 0.3-10 \mathrm{sec} \\
T_{D} & : 0.1-5 \mathrm{sec}
\end{array}
$$

\section{Summing up}

(1) We have measured the dynamic property of each component part of our control system with the following results:

(a) Transfer function $G_{d}(s)$ of the detector is:

$$
G_{d}(s)=\frac{k_{d}\left(1+T_{e} s\right) e^{-L d s}}{\left(1+T_{d} s\right)\left(1+T_{c} s\right)}
$$

(b) Transfer function $G_{f}(s)$ of the final control element is:

$$
\begin{aligned}
G_{r}(s) & =G_{a}(s) \cdot G_{n}(h / a) \cdot G_{r}(s) \\
& =\underset{k_{v} \cdot k_{a} \omega^{2}{ }_{n a} \cdot G_{N}(h / a)}{\left(s^{2}+2 \xi_{a} \omega_{n a} s+\omega^{2}{ }_{n a}\right)\left(1+T_{1 v} s\right)\left(1+T_{2, r} s\right)}
\end{aligned}
$$

(c) The open-loop transfer function of the control system without a controller is:

$$
\begin{aligned}
G_{t}(s) & =G_{p}(s) G_{d}(s) G_{f}(s) \\
& =\frac{k_{t} \omega^{2}{ }_{p p}\left(1+T_{p} s\right) e^{-L d s}\left(1+T_{t} s\right)}{\left(s^{2}+2 \xi_{p} \omega_{n p} s+()^{2}{ }_{n p}\right)\left(1+T_{d} s\right)\left(1+T_{e} s\right)}
\end{aligned}
$$

$$
\cdot \frac{\omega^{2}{ }_{n a} \cdot G_{N}(h / a)}{\left(1+T_{1} s\right)\left(1+T_{2,} s\right)\left(s^{2}+2 \xi_{a}\left(\omega_{n a} s+\left(\nu^{2}{ }_{n a}\right)\right.\right.}
$$

(2) The measured values of the periodic time of sustained oscilations almost agree with the values calculated from open-loop transfer function $G_{t}(s)$.

(3) We have designed an electric PID controller which fits this system. Its specifications are:

$P \quad:$ : 0.3-20 (Proportional band 300-5\%) Continuous variable

$T_{I} \quad: 0.3-10 \mathrm{sec}$ steplessly variable

$T_{D}: 0.1-5 \mathrm{sec}$

\section{Literature Cited}

[1] Ihara, Sato; J. Text. Mach. Soc. Japan, II, 2 (1965)

[2] Ihara, Sato; ditto, 13, 4 (1967)

[3] Kuo; Automatic Control Systems, P.461 Prentic-Hall, Inc.

[4] Gibson; Nonlinear Automatic Control, P.362, McGrow-Hill Book Co. 